\title{
Mathematical Analysis and Simulation of Ahrens Model in Pulse Combustor
}

\author{
Suresh Sorathiya, M.B. Prajapati
}

\begin{abstract}
Ahrens model accepted large data of Kilicarslan but with some real differences. In Kilicarslan model, released heat in combustion having more $I^{2} R$ that is released under Ahrens. As per Ahrens if any specific object divides reaction and cool zone then heat release / cycle is very less compare with Kilicarslan. But with one condition of one object that is, it should be pressure independent otherwise density of reactants remains constant (or not enough increased); as a result, more heat released with less satisfied output. Mathematical model of Ahrens brief about object zones and its separation. This paper also brief about dynamic work function of tailpipe with adjustment of frequency which will proceed for system stability and its accuracy.
\end{abstract}

Keywords: Burning Mass Equation, Frequency Analysis, Roll of Oscillation, Stability, Modified Ahrens Equation

\section{INTRODUCTION}

Ahrens model is Kilicarslan's modified model. Assuming the separation of two zones is possible by introducing thin flame sheet between them. Now process of heat spanning combustion chamber cross section with two zones, where pressure is independent and criteria of Rayleigh satisfied [1].

Above mathematical process indicates $2^{\text {nd }}$ order differential equation, similar given by Kilicarslan but not constant damping. So as per Ahrens released heat is mathematically damped oscillation graph. Because at $\mathrm{t}_{0}$ time reactants having low pressure and at $2^{\text {nd }}$ piece of cycle it increases (at $3^{\text {rd }}$ it stabilized again and last cycle again pressure is low). Ahrens used pulse combustor for stabilization with some parameters having fixed flame speed.

\section{MATHEMATICS OF MODEL}

\section{A. Stabilized Energy}

In Kilicarslan model equations gases are in perfect and ideal condition and ratio of heats are constant at the end of $4^{\text {th }}$ cycle in reactants. So total Constant combustion energy $E_{c c}$ is uniform in two separated zones. For separating two zones five major calculations need to be focused: 1. Energy Stability, 2. Rate of change of burning Mass, 3. Reaction of combustion chamber, 4. Reaction of change in mass and 5.

Revised Manuscript Received on January 05, 2020.

Suresh Sorathia*, Mathematics department, HNGU Patan, Patan, INDIA Email: Suresh.sorathia@sal.edu.in

Dr. M.B. Prajapati, Mathematics department, HNGU Patan, Patan, INDIA. Email: hod_mathsngu@yahoo.com
Area covered before and after burning process. That is why, Defined equation which is same as Kilicarslan [3].

$$
\frac{\mathrm{d}}{\mathrm{d} t}\left(E_{c c}\right)=\dot{Q}+h_{r} \dot{m}_{r}-h_{e} \dot{m}_{e}
$$

Where, Ecc=Total Energy output, Q= Rate of change of released heat, $m_{r}$ and $m_{e}$ are mass flux in out in combustion chamber respectively. $H_{r}$ and $h_{e}$ are amount of enthalpy of reactance and products, while heat being released.

Total energy equation while combustion chamber is in process of releasing heat.

$$
E_{c c}=\frac{P V_{c c}}{\gamma-1}
$$

Where, Gamma $=\mathrm{Cp} / \mathrm{Cv}$ is heat constant. $\mathrm{V}_{\mathrm{cc}}=$ Total Volume while heat release. And $\mathrm{P}$ is constant pressure.

Now rate of heat release in combustion chamber is:

$$
Q=m_{b} *\left(\Delta H_{f} /(1+r)\right)=m_{b}\left(h_{e}-h_{r}\right)
$$

Where, $\mathrm{m}_{\mathrm{b}}=$ Burning amount of mass of reactant, Delta_ $\mathrm{H}_{\mathrm{f}}$ heat of combustion per mass of fuel, $r$ is amount of air used in fuel burning process.

Note: Kilicarslan assumes that the quantity of rate of change of burning and releasing mass are equal. Where as Ahreans says they are different [1].

\section{B. Rate of Change of Burning Mass}

Burning rate indicates how much amount of heat released. Also specify the reaction of mixture and content, amount for cycle. Burning amount is cause of separating two zones where reactants having unburned material and products has burnt gases. If burning speed (product material) per cycle in cross section is depends on density of reactant, cross section area and its relative speed then total rate of change of mass burning is:

$$
m_{b}=\rho_{r} * A_{b} * U_{f}
$$

Where, $m_{b}=$ Burning amount of mass of reactant, Rho_(r)= Density, $A_{b}=$ Cross Section Area for burning process and $\mathrm{U}_{\mathrm{f}}=$ Flame speed. If $\mathrm{T}_{0}=$ is initial time where pressure is initiated which is constant in entire process then burning equation is defined by [5]:

$$
m_{b}=\left(P / R \dot{T}_{0}\right) * A_{b} * U_{f}
$$

$\mathrm{R}=$ Specific Gas Constant 


\section{Process of Combustion Chamber}

If related reactive mass is present (Unburn material after burning process) then it is difference of rate of change of reactant mass and burning mass denoted by:

$$
\frac{\mathrm{d} M_{r}}{\mathrm{~d} t}=\dot{m}_{r}-\dot{m}_{b}+I^{2} R \quad \text { (Author Equation) }
$$

Ideal situation R.H.S. is zero in every cycle.

$$
\int_{\text {Cycle }}^{x}(m r-m b)^{\circ} \sim 0
$$

- It near to zero cause of heat loss.

\section{Rate of Change of Mass Flow}

Above derivation and previous paper of Kilicarslan [3] describe how and what amount of change is possible while burning process.

Based on that mass change in reactant is:

$$
m r(t)=k_{g} *(1+r) * \sqrt{|p|} 1_{(-x, 0)}(p)
$$

$\mathrm{K}_{\mathrm{g}}=$ Constant flow parameter, $1_{\mathrm{X}}(x)=$ indicator function, $x$ is element for negative reactant in $\mathrm{X} \subset \mathrm{R}$ and Zero otherwise.

The value of $\mathrm{K}_{\mathrm{g}}$ is:

$$
k_{g}=\sqrt{2 * p_{g}} * C_{D, g} * A_{v, g}
$$

- Where, $\mathrm{P}_{\mathrm{g}}$ is density of gas, $\mathrm{C}_{\mathrm{dg}}=$ Discharge Coefficient of gas valve, $A_{v g}=$ Effective flow area of gas pipe and $\mathrm{r}=$ gas to fuel Ratio.

\section{E. Total Density of Release in Cross Section Area}

Let suppose, $\mathrm{L}_{\mathrm{et}}=$ Tail Pipe Length, $\mathrm{A}_{\mathrm{tp}}=$ Tail Pipe Cross Section Area, $\mathrm{m}_{\mathrm{e}}=$ Leaving Mass after burning process per cycle.

$$
L_{t p} *\left(\frac{d *\left(m_{e}\right)}{d t}\right)=\rho A_{t p}
$$

\section{FREQUENCY EQUATION AND ANALYSIS}

After covering above process, equation leads to linear (In ideal condition it is linear: Zero R.H.S.) per cycle but damping reactance is not linear.

The equation can be written as:

$$
\ddot{x}+h_{(x, x)+\left(w_{0}\right)^{2} x \sim 0}
$$

Where, $x=p(t)$ and dot represent time derivation. The nonlinear damping term is $\mathrm{h}\left(\mathrm{x}, \mathrm{dot} \_\mathrm{x}\right)$

$$
\left.h_{(x, x)}=-\left(A * F^{\prime}(x)+B\right) x\right)
$$

Where $F^{\prime}(x)$ is:

$$
F^{\prime}(x)=-\frac{1}{2 *(\operatorname{Root}|P|)} *\left(1_{(-x, 0)(X)}\right)
$$

In $F^{\prime}(x)$ having negative sign (Due to realising heat) $\leq 0$, that is why damping is non-linear. And final equation of non-linear reactant frequency is:

$$
f_{0}=\frac{(\gamma-1) * h_{e}}{2 * P i} *\left(\sqrt{\frac{A_{t p}}{V_{c c} * L_{t p}}}\right)
$$

\section{OSCILLATION STABILITY}

Finding stable oscillation, need to defined the value of maximum amplitude value of the oscillation. For satisfying stability criteria what is the value of realising heat in stable oscillation and unstable maximum value needed.

$$
\int_{C y c l e}^{x}(m r-m b)^{x} \sim 0
$$

Based on above equation,

The maximum value of unstable oscillation is:

$$
p_{\max }=\left(\frac{2 I}{\pi}\right)^{-1} *\left(\left(P_{0} *(1+\gamma) * h_{r}\right) /\left(\Delta H_{f}\right)\right)
$$

And the value of stable oscillation is:

$$
U_{f}=\left(\frac{I}{2 * \pi}\right)^{0.5} *\left(\frac{\left.R T_{0} *(1+\gamma)^{3 / 2}\right)}{A_{b} *\left(P_{0}\right)^{0.5}}\right) * \sqrt{\left.\left(h_{r}\right) /\left(\Delta H_{f}\right)\right)}
$$

Where I is integral Factor that describe the Shape of curve.

$$
I=\left(\frac{1}{2 * T_{p}}\right) * \int_{\text {Cycle }}^{x} \sqrt{\mid p \hat{(t) \mid} * 1_{(-x, 0) *(p \hat{(t)})}} d t
$$

\section{RESULT AND SIMULATION}
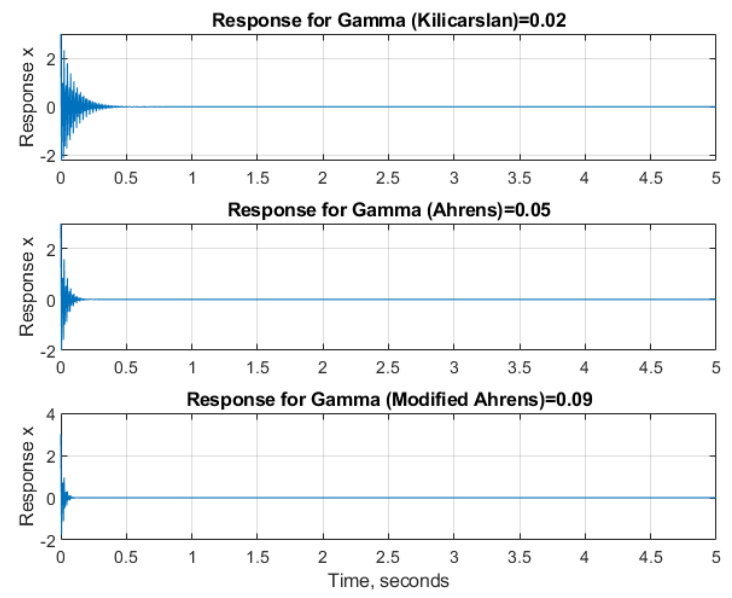

Figure 1. Comparison of previous v/s modified models

Published By: 

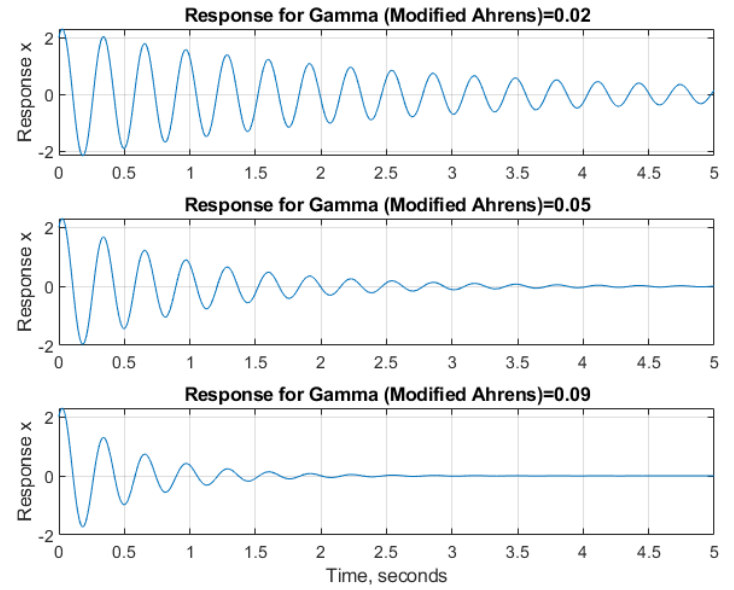

Figure 2. Adjustment of less difference heat constant (Gamma tens to zero)
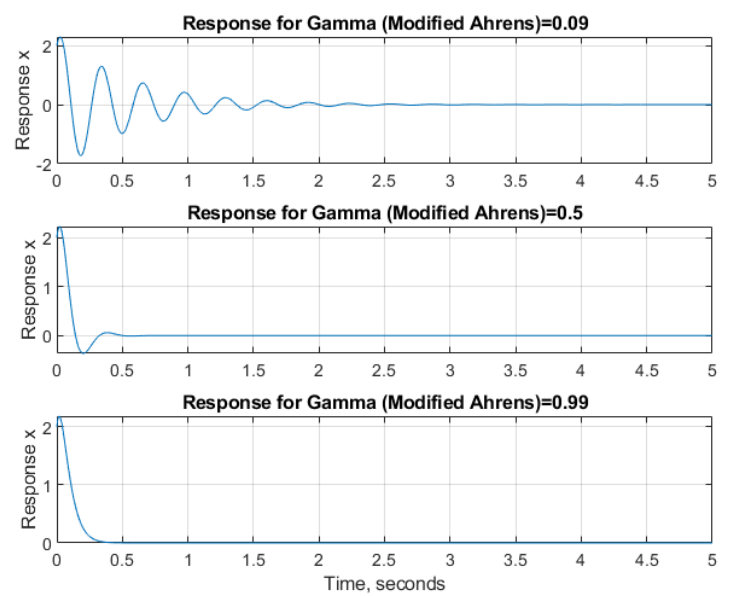

Figure 3. Adjustment of large difference heat constant (Gamma zero to One)

TABLE 1: COMPARISON

\begin{tabular}{|l|l|l|l|}
\hline Parameter & Kilicarslan & Ahrens & $\begin{array}{l}\text { Modified } \\
\text { Ahrens }\end{array}$ \\
\hline Total Energy & Low & Moderate & High \\
\hline Heat & High & Moderate & Low \\
\hline $\begin{array}{l}\text { Burning } \\
\text { Mass }\end{array}$ & Minimum & Moderate & Maximum \\
\hline $\begin{array}{l}\text { Unburned } \\
\text { Material }\end{array}$ & More & Moderate & Less \\
\hline Oscillation & Unstable & $\begin{array}{l}\text { Marginal } \\
\text { Stable }\end{array}$ & Stable \\
\hline Curve (I) & Sharp & $\begin{array}{l}\text { Conditional } \\
\text { Smooth }\end{array}$ & Smooth \\
\hline
\end{tabular}

\section{FLOW CHART}

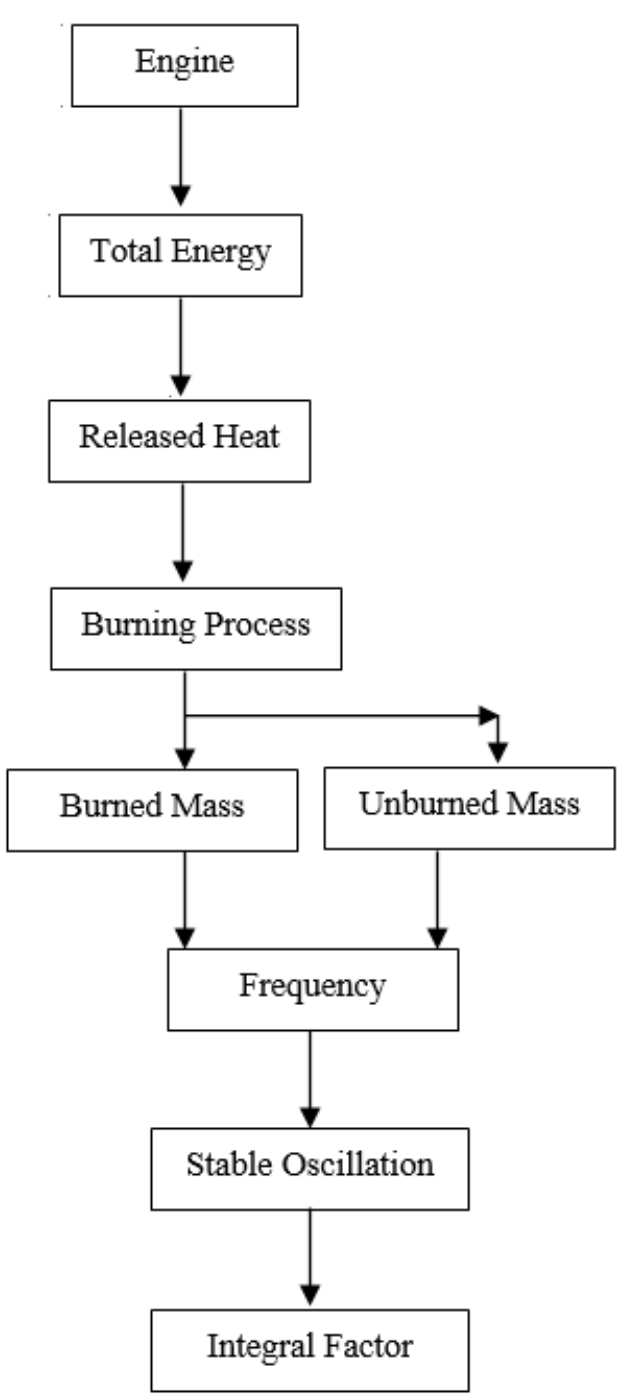

VII. CONCLUSION

Based on above mathematical equation and stabilized oscillation condition, We conclude that little modification in Ahrens model in analysis will give smoothest output compare to Kilicarslan and Ahrens while releasing heat in pulse combustor [Reference figure 3]

Pulse combustor age and average is increased by this process and it can chase 10 times higher frequency compare with initial conditions. Flame speed is also potential as per user requirement.

Figure 2 is simulated result of High constant pressure in Low volume. In this condition if constant pressure is very high for even a second that will create large oscillation which will damage the system and accordingly.

Figure 3 is simulated result of variation of pressure vs volume. When both are same it always in moderate condition due to its inverse proportionality. Means when this ratio tends to one, it creates nearly zero oscillation. Which will be required for any system. 


\section{ACKNOWLEDGEMENT}

I would like to thanks to my colleague prof. Kuldeep Shukla. I also thank those who help me directly and indirectly in this paper.

\section{REFERENCES}

1. Suresh Sorathia and Dr. M.B. Prajapati, "Review: Future scope in mathematical modelling of pulse combustor suggested by Kilicarslan", IJIRAS, Vol-4, Issue-8, Aug. 2017.

2. Suresh Sorathia and Dr. M.B. Prajapati, "Review: Future scope in mathematical modelling of pulse combustor suggested by Ahrens At. Al", IJFRCSCE, Vol-4, Issue-4, Apr. 2018, PP.No. 156-157.

3. Suresh Sorathia and Dr. M.B. Prajapati, "Mathematical Analysis and Simulation of Kilicarslan Model in Pulse Combuster", IJIRAS, Vol-5, Issue-12, Dec. 2018, PP.No. 183-185.

4. P.K.Barr, "Pulse Combustion Modelling Demonstrated of the importance of characteric times", combustion and flame, vol-82, PP. No. 252-269, Year: 1990.

5. Ben T Zinn, "Pulse Combustion: Recent Applications and Research Issues", The combustion Institute, Year-1992, PP.No: 1297-1305.

6. Wu Zhonghua, "Mathematical Modeling of Pulse Combustion and its Applications to Innovative Thermal Drying Techniques", Tayler and Francis, Jun 2007, PP.No: 941-942

7. Yanying Xu, Peng Dong, Ming Zhai, Qunyi Zhu, "Heat Transfer in Helmholtz-Type Valveless Self-Excited Pulse Combustor Tailpipe" Asia Pacific Power and Energy Engineering Conference 2012, pp. 1-4, Year 2012, DOI: 10.1109/APPEEC.2012.6307021.

8. Yanying Xu; Jian Chen; Ruojun Wang, "Combustion Simulation of a Helmholtz-Type Valveless Self-Excited Pulse Combustor” Asia Pacific Power and Energy Engineering Conference 2012, pp. Pages: 1 - 4, Year 2012, DOI: 10.1109/APPEEC.2012.6307046

9. Yanying Xu; Ming Zhai; Peng Dong; Fei Wang, "Experimental Research on Operational Characteristics of a Helmholtz-Type Valveless Self-Excited Pulse Combustor," Asia Pacific Power and Energy Engineering Conference 2011, pp. 1-4, Year 2011, DOI: 10.1109/APPEEC.2011.5749014.

10. J. Chato; J. Defina; K. Armstrong; W. D. Jackson; M. Khesin, "Determination of the NOx emission reduction potential of an aerodynamically valved pulse combustor" Energy Conversion Engineering Conference, 2002. IECEC '02. 2002 37th Intersociety, pp 393 Year 2002, DOI: 10.1109/IECEC.2002.1392058. 